\title{
Seria viável uma terceira via entre Newton e Leibniz: A Filosofia Natural de Boscovich
}

\author{
A third way between Newton and Leibniz would be viable: Boscovich's Natural Philosophy \\ Wigson Rafael Silva da Costa*1] ${ }^{*}$, Antonio Augusto Passos Videira10 \\ ${ }^{1}$ Universidade do Estado do Rio de Janeiro, Rio de Janeiro, RJ, Brasil.
}

Recebido em 21 de junho de 2020. Revisado em 04 de agosto de 2020. Aceito em 12 de agosto de 2020.

\begin{abstract}
O presente artigo pretende abordar os aspectos principais da Filosofia natural do jesuíta Ruggero Giuseppe Boscovich e tenta enfatizar a consistência entre as reflexões que fomentou para elaboração de sua obra magna Theoria Philosophiae Naturalis, e a discussão do século XVIII no tocante a oposição entre as perspectivas de Isaac Newton e Gottfried Leibniz, uma oposição que continuou mesmo após suas mortes.

Palavras-chave: Boscovich, Filosofia natural, Newton e Leibniz.
\end{abstract}

\begin{abstract}
This article explores the main aspects of the Natural philosophy of the Jesuit Ruggero Giuseppe Boscovich and tries to stress the consistency between the reflections he fostered for the elaboration of his great work, Theoria Philosophiae Naturalis, and the eighteenth-century discussion on the opposition between the perspectives of Isaac Newton and Gottfried Leibniz, an opposition which continued even after their deaths.

Keywords: Boscovich, Natural philosophy, Newton and Leibniz.
\end{abstract}

\section{Introdução}

Ruggero Giuseppe Boscovich nasceu em Dubrovnik uma cidade costeira localizada no extremo sul da Dalmácia - no ano de 1711. Iniciou sua formação no Colégio Jesuíta de sua cidade, onde recebeu uma base completa de latim e grego. Em 1725, Boscovich, que desde os quatorze anos havia decidido tornar-se um jesuíta, mudou-se para Roma. Ali, prosseguiu com os estudos no noviciário jesuíta de Sant'Andrea, onde aprofundou seus conhecimentos sobre os clássicos e a retórica, e após o habitual treinamento na vida religiosa Boscovich fez seus primeiros votos como jesuíta em 1727. Posteriormente, quando se transferiu para o Colégio Romano, o primeiro e mais importante dos colégios jesuítas, Boscovich demonstrou talento e amplo interesse nas disciplinas de cunho teológico e em questões concernentes às ciências [1, p. 488].

Em 1740, graças ao seu amplo conhecimento e reputação, Boscovich foi nomeado para a cadeira de matemática no Colégio Romano. Seu período em Roma foi inegavelmente prolífico e de intensa atividade, haja vista que o jesuíta produziu uma grande quantidade de publicações, cerca de sessenta livros ou opúsculos sobre temas científicos, envolvendo matemática, óptica, astronomia, geodésia e as marés. Destas obras, nos convém destacar: De viribus vivis (1745); De lumine (1748) e sua obra magna Theoria Philosophiae Naturalis (1758) que, por ocasião, foi concluída no transcurso de uma das suas missões diplomáticas, em Viena [2, p. 326]. O filósofo

*Endereço de correspondência: wigsonrafael11@yahoo.com.br natural dalmaciano faleceu no dia 13 de fevereiro de 1787 , em Milão.

No presente artigo, abordaremos os traços mais característicos da física de Boscovich, com enfoque no livro Theoria Philosophiae Naturalis, passando pelas suas discussões metodológicas e também pelas influências das figuras de Isaac Newton (1642-1727) e Gottfried Leibniz (1646-1716) na vida e obra do jesuíta.

\section{Boscovich: Um jesuíta entre os sistemas de Newton e Leibniz}

Isaac Newton e Gottfried Leibniz revelaram-se figuras determinantes na vida intelectual de Boscovich. No que diz respeito ao primeiro, foram nos anos do Colégio Romano que o jesuíta tomou contato com duas importantes obras do filósofo natural inglês Óptica ou Um tratado das Reflexões, Refrações, Inflexões e Cores da Luz e Princípios matemáticos da filosofia natural, convertendo-se em um entusiasmado propagador da nova filosofia natural. No tocante a Leibniz, já por volta de 1745, Boscovich se debruçou sobre algumas questões que emergiam das obras do filósofo natural alemão, um esforço que resultou em uma importante dissertação, De viribus vivis, que tinha como objeto de investigação a vis viva proposta por Leibniz. [2, p. 326-30].

Sendo patente a relação de Boscovich com os dois filósofos naturais supracitados, não deve surpreender o fato de, no começo da Theoria philosophiae naturalis, o jesuíta afirmar enfaticamente que seu sistema teórico está a meio caminho entre o de Leibniz e o de Newton [3, p. 
35]. Tal afirmação nos indica que as reflexões empenhadas pelo jesuíta em sua obra magna encaixam-se no debate de seu tempo destinado a resolver a oposição entre as perspectivas de Newton e Leibniz, oposição esta que permaneceu aberta após suas mortes [4, p. 90].

$\mathrm{O}$ interesse de Boscovich pela teoria newtoniana e pela matemática se manifestaram desde muito cedo, conforme indicamos em nosso breve apanhado biográfico. Em vez do cálculo desenvolvido por matemáticos como d'Alembert, Bernoulli e Euler, o jesuíta preferiu o método geométrico de magnitudes infinitamente pequenas que Newton quase sempre usava [2, p. 330]. Boscovich o teria aplicado particularmente a problemas de geometria diferencial, mecânica terrestre e celeste e astronomia prática. Em 1740, ele estudou as propriedades dos círculos osculatórios e, em 1741, dedicou um tratado inteiro à natureza das magnitudes infinitamente grandes e pequenas empregadas nesse método. No entanto, embora fosse um grande admirador da física newtoniana, o jesuíta não deixou de adotar uma postura crítica em relação ao modelo teórico do inglês.

Desde dos estudos de Boscovich sobre refração, destaque para a obra De lumine (1748), são sentidas as fragilidades da teoria newtoniana. De modo que não tardou até que o jesuíta compreendesse a necessidade de se fazer uma modificação, pelo menos parcial, na base teórica da pesquisa de Newton a fim de salvar sua configuração geral e os importantes resultados alcançados. Após rever as ideias newtonianas referentes à estrutura da matéria e às leis de interação entre partículas microscópicas, a reflexão subsequente de Boscovich foi estimulada pela dinâmica leibniziana e nela o jesuíta teria encontrado o caminho para aperfeiçoar os resultados obtidos por Newton [4, p. 97]. Mas o que teria levado Boscovich a fazer este movimento em direção à dinâmica leibniziana? A fim de respondermos tal questionamento e de termos uma compreensão mais ampla acerca das escolhas teóricas de Boscovich nos convém apresentar, nas páginas subsequentes os traços mais característicos das dinâmicas de Newton e Leibniz.

\section{A física de Newton ou a dinâmica a serviço da geometria}

As leis de Kepler eram amplamente difundidas e reconhecidas quando Newton traçou como um dos objetivos do seu Principia a explicação das respectivas leis que, segundo ele, não puderam ser adequadamente compreendidas pelo modelo cartesiano dos vórtices 11 Opondo-se à

\footnotetext{
1 Na seção IX do livro II do Principia, Newton desfere um duro ataque a teoria dos vórtices por meio de uma análise matemática das condições dinâmicas do movimento turbilhonar. Da sua análise, duas conclusões condenatórias emergiram: No Corolário IV, destacase a incapacidade de um vórtice em se sustentar. Sua manutenção em uma condição estável exigiria a transferência constante de movimento de uma camada para outra, até, na leitura de Newton, ele ser exaurido e se perder na infinitude do espaço. Deste modo, um vórtice sem uma fonte contínua de energia nova, ou movimento novo, deveria decair. No Escólio, Newton expõe que os períodos de
}

Descartes, Newton elaborou um modelo dinâmico pautado no conceito de força, que não seria um mero artifício matemático, visto que, na dinâmica newtoniana, a força possui uma realidade física, muito embora não seja tarefa do livro I dos Principia investigar tal realidade [5, p. 399]

Seguindo as primeiras definições de sua obra magna, Newton nos apresenta três tipos de força. A primeira delas seria a força inata da matéria, um poder de resistir, através do qual todo corpo, no que depende dele, mantém seu estado presente, seja ele de repouso ou de movimento uniforme em linha reta [6, p. 40]. "Força" é chamada a qualidade da inércia, entendida como a capacidade de resistir e preservar um estado de repouso e o impulso diante de um obstáculo que se opõe à resistência e a tendência de superar essa oposição. Na prática, a inércia é caracterizada por uma ambivalência essencial: a resistência se o corpo estiver em repouso e o impulso se o corpo estiver em movimento. Embora não seja, neste caso, a causa do movimento, o termo força ainda poderia ser empregado para se referir à qualidade da inércia, pois, ao se comprometer com a interpretação peripatética, Newton aposta na natureza dual da força: parcialmente ativa, na medida em que influencia outros objetos e parcialmente passiva, pois seria suscetível a modificações externas [4, p. 91].

Os outros dois tipos de força - impressa e centrípeta - são apresentadas nas definições subsequentes. A força imprimida, àquela que consiste na causa do movimento, é uma ação exercida sobre um corpo a fim de alterar seu estado, seja de repouso, seja de movimento uniforme em uma linha reta. São deste tipo: percussão, de pressão e a própria força centrípeta. Quanto a última, a qual se encaixa a gravidade, pode-se defini-la como aquela pela qual os corpos são dirigidos ou impelidos, ou tendem, de qualquer maneira, para um ponto ou centro [6, p. 41].

As observações feitas em torno da força centrípeta constituem, portanto, o núcleo duro da teoria da gravitação de Newton, sendo a força da gravidade aquela que depende da distância e devido à qual os corpos tendem para o centro da terra, sendo ainda a mesma em distâncias iguais. A configuração do sistema solar se deve sobretudo a esta força, uma vez que haveria forças centrípetas dirigidas aos corpos do Sol, da Terra e dos outros planetas e se não fosse por elas os planetas voariam para longe de suas órbitas em linha reta, com um movimento uniforme. Mas como se daria a "influência gravitacional" do Sol sobre os planetas e dos planetas sobre o Sol? Nas páginas do Óptica, de 1704, Newton especula que seja graças a uma "virtude" ou "poder" que possibilitaria as partículas e corpos influenciarem-se mutuamente à distância.

Este clássico de Newton é dividido em três partes: a primeira tem como assunto principal o estudo da refração (principalmente em prismas) e sua relação com as cores; a segunda parte trata, principalmente, do fenômeno das

rotação variam em um vórtice cartesiano com o quadrado do raio, ao passo que a terceira lei de Kepler, baseada nos fenômenos celestes, exige $3 / 2$ como potência. Para o inglês, pareceria impossível explicar esse fenômeno da potência $3 / 2$ pela teoria dos vórtices de Descartes. $[7]$. 
cores que podem ser observadas em corpos transparentes finos e que, contemporaneamente, denominamos fenômenos de interferência da luz; a terceira parte, enfim, apresenta um estudo sucinto sobre fenômenos de difração da luz. Nas Questões do Óptica, 2 a parte mais especulativa da obra, Newton se aproxima do corpuscularismo e isto se deve principalmente porque o cientista inglês após tomar contato com as obras Experimentos e considerações a respeito das cores (Robert Boyle) e Fisiologia EpicuroGassendo-Charltoniana (Walter Charleton), foi levado a uma teoria corpuscular da luz e uma teoria atômica da matéria. [8, p. 4202] Será justamente no bojo de suas concepções corpusculares que Newton presumirá que as partículas são capazes de agir à distância e influenciarem umas às outras. Na questão 31 do Óptica, ele nos diz:

Não têm as pequenas partículas dos corpos certos poderes, virtudes ou forças por meio dos quais elas agem a distância não apenas sobre os raios de luz, refletindo-os, refratandoos e inflectindo-os, mas também umas sobre as outras, produzindo grande parte dos fenômenos da natureza? $[9, \text { p. } 274]^{3}$

Em face disto, parece-nos oportuno destacar que apesar de Newton estar integrado àquela tradição filosóficocientífica que tornou os primeiros elementos da realidade átomos materiais, alguns aspectos inovadores em sua reflexão o distinguem dos seus correligionários. Por um lado, o inglês permanece dentro da respectiva tradição na medida em que concebe os corpos como constituídos por partículas extensas cujos movimentos e posições que assumem dão origem a todos os fenômenos observados. Em Newton, embora o átomo deva ser visto como uma entidade dinâmica, capaz de sofrer e exercer força, ele ainda é dotado de materialidade [4, p. 96]. Por outro lado, enquanto os materialistas mais radicais, como os cartesianos, consideravam as partículas corpusculares como os elementos indivisíveis que compõem a matéria, optando por explicar sua coesão exclusivamente por meio do contato imediato, o cientista inglês considerava a possibilidade de que essas partículas estivessem conectadas à distância e mantidas juntas por forças atrativas. Nas palavras de Newton:

As partes de todos os corpos homogêneos duros que se tocam completamente uns aos outros se ligam muito fortemente. E, para explicar como isso ocorre, alguns inventaram átomos em forma de ganchos, o que é incorrer em petição de princípio; e outros nos dizem que os corpos se colam pelo repouso (isto é, por uma qualidade oculta, ou melhor, por nada); e outros, que eles se ligam por movimentos solidários (isto é, por um repouso

\footnotetext{
2 Tais "questões" não são, na verdade, perguntas nem dúvidas e sim conjeturas ou hipóteses, formuladas como se fossem questões [8, p. 4202-27].

3 Os autores agradecem ao Prof. Msc. Carlos Cesar Costa (UFMA) pelo compartilhamento da edição brasileira do Óptica.
}

relativo entre eles mesmos). Eu, ao contrário, inferi de sua coesão que suas partículas se atraem por alguma força que no contato imediato é extremamente forte, a distâncias pequenas executa as operações químicas acima mencionadas e não vai muito além das partículas com algum efeito perceptível [9, p 281]

Uma vez que as partículas de matéria estão conectadas por atração mútua, Newton confere à força uma qualidade importante: a força de repulsão deve se fazer presente quando a força de atração cessa. Isto se aplicaria em diferentes casos de relação entre as partículas, que ora estão conectadas em agregados, possibilitando a formação dos corpos (evidenciando o caráter atrativo da força); ora se repelindo sem que seja possível estabelecer qualquer tipo de contato entre elas (evidenciando o caráter repulsivo da força). A segunda situação ocorre no caso das superfícies reflexivas. Estando Newton convencido de que o feixe de luz, como o restante da matéria, era composto de corpúsculos, o fenômeno de refração poderia ser explicado pelo fato de que as partículas do corpo reflexivo repelem as da luz à medida que se aproximam $[4, \mathrm{p}$. 95]. Assim, para explicar os diferentes tipos de relações entre os elementos atômicos que a experiência mostrava, era necessário que a força, que os regula, operasse em duplo registro: ora atraente, ora repulsiva.

No entanto, a teoria corpuscular gerava também inúmeras lacunas e dificuldades internas para Newton, sobretudo no que se refere à conciliação entre a teoria corpuscular da luz e alguns dos fenômenos de natureza óptica [4, p. 96-97]. Uma de suas principais dificuldades, por exemplo, consistia em explicar os fenômenos de "inflexão" ou difração da luz, uma debilidade que não passou desapercebida ao próprio Newton. Sua insatisfação com alguns aspectos de sua pesquisa é sentida em uma passagem do Livro III de seu tratado:

Quando fiz as Observações precedentes, tinha a intenção de repetir a maioria delas com mais cuidado e exatidão e de fazer algumas novas para determinar a maneira como os raios de luz se curvam ao passar perto dos corpos para produzir as franjas de cores com as linhas escuras entre elas. Mas fui então interrompido e não posso pensar agora em submeter essas coisas a novas considerações. E, como não terminei essa parte do meu projeto, concluirei propondo apenas algumas questões na expectativa de que uma pesquisa adicional seja feita por outros ([9], p. 250)

Portanto, parece ter sido muito menos por temor às críticas de Robert Hooke e muito mais por reconhecer que não possuía uma teoria definitiva sobre a luz que o cientista inglês teria tardado a publicação do Óptica em mais de nove anos, e sendo assim levado a colocar no final de seu trabalho uma série de "questões", no lugar de afirmações, demonstrando que sua teoria da óptica estava incompleta [8, p. 4202-27]. 


\section{A física de Leibniz ou a geometria a serviço da dinâmica}

A despeito da popularidade da nova filosofia mecânica e de sua ambição em explicar os fenômenos naturais em termos de matéria e movimento, Leibniz mostrou-se um dos críticos mais penetrantes das concepções dominantes da matéria na tradição mecanicista, que tinha em Descartes um dos seus mais proeminentes representantes. Em uma das suas críticas à concepção mecânico-atomista, o filósofo natural alemão aponta para um ponto de tensão entre o Princípio de Continuidade - segundo o qual nenhuma mudança ocorre através de saltos - e a noção de que os átomos devem ser perfeitamente rígidos e inflexíveis, tendo em vista que a colisão de dois átomos levaria a uma mudança descontinua na natureza Isto equivale dizer que, sendo os átomos incapazes de flexionar, suas direções e velocidades teriam que mudar instantaneamente após o contato, violando, portanto, o Princípio de Continuidade. Leibniz opta por salvaguardar o respectivo princípio e, em razão disto, insiste que a continuidade pressupõe elasticidade Por menores que sejam, todos os corpos devem ser elásticos, arguirá o filósofo [10].

Em outro momento, Leibniz evoca o Princípio de Plenitude para contrapor a ideia de um espaço vazio entre os átomos e também a possibilidade de átomos indivisíveis, visto que, segundo o filósofo natural alemão, não importa o quão pequeno imaginamos que os átomos sejam, desde que eles sejam considerados internamente simples e homogêneos, o mundo ainda poderá conter mais variedade, riqueza e existência, se forem divididos. Assim sendo, Leibniz defenderá que todas as partes da matéria podem ser divididas ao infinito e esta divisão infinita parece ser suficiente para descartar qualquer imagem padrão do atomismo material, já que qualquer corpo que possa reivindicar ser um átomo indivisível seria, na verdade, subdividido em subcorpos menores, contradizendo a própria definição de átomo [10].

$\mathrm{Na}$ esteira disto, em contraposição à explicação cartesiana da matéria segundo a qual a essência da matéria é extensão, Leibniz argumenta que nenhum corpo cuja essência seja simplesmente extensão poderia ser considerado uma substância, pois sendo todo corpo extenso composto de partes, pelo critério da independência, as partes serão ainda mais fundamentalmente reais do que os corpos que compõem. Se aquilo o que denominamos substância deve apresentar uma unidade real [11, p. 184], isto é, deve ser absolutamente indivisível, a infinita divisibilidade da matéria extensa demonstra que a extensão não pode ser característica fundamental das verdadeiras unidades elementares [4, p. 100]. Leibniz sustentará, então, que a qualidade essencial da substância simples deverá ser reconhecida em vis viva, um conceito que esteve no epicentro de uma conhecida controvérsia entre os cartesianos e Leibniz, que acreditava que a vis viva ou força viva $\left(m v^{2}\right)$,e não a quantidade de movimento $(m|v|)$, era a verdadeira medida da força de movimento e ainda a quantidade conservada no Universo [12, p. 340].
O conceito de força leibniziano apresentava diferenças daquele adotado pela escola de Newton, deixando de ser um modo de operação mecânico e se tornando uma atividade quase vitalista No contexto da física leibniziana, a força viva representa uma medida da capacidade de um corpo de produzir efeitos em virtude de seu movimento [10]. Seria graças a essa força que um dado corpo pode transmitir seu movimento a um corpo mais lento ou se elevar a uma determinada altura. Ademais, a força viva empregada para tal corpo se elevar a certa altura seria igual a força viva que o mesmo corpo ganharia ao cair da mesma altura. Isto nos permite inferir que o conceito leibniziano de força é o que hoje chamamos de energia cinética, porém concebida como inerente a matéria $[13$, p. 201]. Pierre Costabel indica o caminho trilhado por Leibniz rumo ao conceito de força viva:

Leibniz sabia, depois de aprender com Huygens, que a quantidade de movimento no sentido cartesiano (onde a velocidade é considerada apenas em relação à sua magnitude, sem levar em conta o sentido ou a direção) não é conservada no fenômeno de impacto, mas apenas a quantidade de movimento algébrico. Ele aprendeu também o papel desempenhado pela elasticidade e, assim, chegou a uma explicação das verdadeiras leis do impacto; finalmente, ele entendeu a conservação de $m v^{2}$. Consequentemente, ele tinha em mãos elementos de um novo sistema [14, p. 23].

Em posse da força viva, Leibniz ambicionava estabelecer um princípio amplo e absoluto de conservação que formaria a base de seu sistema filosófico e sua descrição do mundo. De acordo com o filósofo natural alemão, a força seria algo diferente do tamanho, da forma ou do movimento, e o corpo não se esgotaria em sua extensão, juntamente com suas modificações. O movimento ou mudança de lugar não seria algo inteiramente real, diferentemente da força viva que seria o que há de real na natureza [15, p. 48-49]. Isto já nos indica que na raiz de sua controvérsia com os cartesianos, a qual trataremos em detalhes mais adiante, não está uma mera disputa matemática quanto à medida da força, $m|v|$ ou $m v^{2}$, mas um desacordo fundemental quanto à própria natureza da força $[16$, p. 32] 4

A força viva despontava para Leibniz como a essência da natureza, a essência da substância simples, a qual

\footnotetext{
4 Deste modo, a ideia basilar do sistema metafísico leibniziano da maturidade é de que há no plano ontológico fundamental unicamente substâncias simples de natureza espiritual. Essas substâncias simples imateriais são, segundo ele, as entidades últimas constituidoras da realidade, devendo ser, portanto, os corpos, enquanto entidades ontologicamente derivadas e secundárias, de alguma maneira redutíveis a elas e delas dependentes. Os corpos são caracterizados por Leibniz como produtos da agregação de mônadas, o que significa dizer que eles são constituídos por elas. Essa relação de constituição não deve ser compreendida, contudo, como sendo uma relação de composição. As substâncias indivisíveis não são partes das quais o corpo seja composto, mas um requisito interno e essencial para a existência deles, pois não se pode conceber a existência do múltiplo sem a existência da unidade [11, p. 187].
} 
o filósofo chamou de mônada. Ao dotar as substâncias simples de força viva, Leibniz afirma que apenas a continuidade da ação, de fato, confere às substâncias seu próprio caráter, ou seja, apenas aquilo que age ininterruptamente pode ser chamado corretamente de substância [4, p. 100]. Sobre isto, no diz o filósofo em seu Sistema novo da natureza e da comunicação das substâncias:

No início, quando me libertei do jugo de Aristóteles, era favorável aos átomos e ao vácuo, porque esse ponto de vista melhor satisfazia a imaginação. Mas, refletindo melhor sobre o assunto, após muito meditar, vi que é impossível encontrar os princípios da verdadeira unidade tão somente na matéria ou em algo que seja apenas passivo [...] Então, a fim de alcançar essas unidades reais, tive de recorrer a um átomo formal, o que pode ser denominado um ponto real e animado ou um átomo de substância [mônada], que deve conter algum tipo de forma ou atividade [vis viva], a fim de produzir um ser completo [17, p. 56-57].

No entanto, também a dinâmica leibniziana apresentou suas debilidades e a controvérsia com os cartesianos nos dá margem para tratar de uma delas. O filósofo natural alemão estava ciente de que para haver a conservação da força viva não poderia haver corpos perfeitamente rígidos no universo e que todas as mudanças na velocidade deveriam respeitar o Princípio de Continuidade. Desta maneira, enquanto uma teoria aceitável da matéria, excluindo a colisão de partículas rígidas, não estivesse disponível, a conservação da força viva não poderia se tornar uma teoria geral da mecânica [18 p. 291]. Leibniz falha neste aspecto. Talvez, porque a construção de um modelo que assegurasse a conservação da força viva passasse pela formulação de uma teoria das forças que o compeliria a aderir ao conceito newtoniano de ação à distância como uma forma de relacionamento dinâmico entre as mônadas, tal como veremos na física de Boscovich. Objetando veementemente a todo o conceito de forças capazes de ação à distância [19, p. 730]. Leibniz formulou uma dinâmica que terminava por abraçar as teses cartesianas segundo as quais o movimento é transmitido através do contato, e para evitar as consequências de assumir partículas perfeitamente rígidas, o filósofo postulou uma matéria "infinitamente fluida" que não continha partes menores. De maneira inesperada, portanto, a pesquisa de Leibniz volta ao ponto de partida. Depois de se esforçar para superar à concepção atômica cartesiana, o filósofo natural alemão opta por recuperar as teses do matemático francês para não ter que admitir a validade dos resultados de Newton [4, p. 101].

\section{A metodologia de Boscovich}

A nossa exposição sobre a metodologia de Boscovich principia com a defesa do jesuíta quanto à existência de três fontes do conhecimento e as limitações do entendimento humano, tendo em vista que Boscovich reconhecia que as dificuldades de aceitação de sua teoria decorriam, principalmente, dos limites cognitivos que caracterizam o homem e, em particular, ao fato dos nossos órgãos sensoriais não serem capazes de captar a realidade em sua completude.

Para Boscovich, o desamparo da humanidade diante dos grandes enigmas do universo é um fato que assombra nossas investigações, haja vista que mesmo o saber adquirido a partir da longa e disciplinada pesquisa sobre a natureza se mostra, em seu entender, ínfimo e não pode ser tomado como algum tipo de conhecimento absoluto sobre o mundo [20, p. 381]. Sendo nosso conhecimento incerto e limitado, inúmeros aspectos da natureza poderiam permanecer ocultos ou serem completamente ignorados pelo espírito humano, sobretudo se concordarmos com a ideia de que os nossos sentidos não nos mostram diretamente o mundo como ele é e seus testemunhos são válidos apenas na medida em que passam pelo crivo da razão ([20], p. 381).

Uma vez que o conhecimento humano provém de três fontes, Boscovich admite, em consonância com sua religiosidade, que a primeira delas é a revelação divina, tendo a fé como fundamento. A segunda fonte de conhecimento seria a experiência sensível que, no entender de Boscovich, pode ser ilusória na medida em que toca apenas na superfície das coisas. Caberia, então, a terceira fonte do conhecimento, a razão, não nos deixar cair nas ilusões provenientes dos sentidos. Boscovich admite que nossa mente possui, por sua própria natureza, instrumentos intelectuais que tornam possível julgar a verdade [20, p. 384]. Deste modo, o jesuíta incentivará os demais pesquisadores a se elevarem para além dos preconceitos dos sentidos e depositarem mais confiança na terceira fonte do conhecimento, a razão [3], p. 111-113].

O jesuíta afirma que um dos problemas enfrentados nesta superação da experiência sensorial reside no fato de nossa linguagem utilizar conceitos adequados à realidade macroscópica. Logo, os termos empregados para descrever a realidade são fortemente afetados pela influência e limitações da experiência sensível, o que impõe aos homens do conhecimento a necessidade de se elevarem para além destes preconceitos sensoriais quando a problemática se volta para a compreensão de uma realidade microscópica.

Nos metais, mármore, vidro e cristais, parece aos nossos sentidos uma continuidade, de modo que não percebemos neles pequenos espaços vazios ou poros; mas a esse respeito, os sentidos tem sido manifestamente enganados. Isso fica claro, tanto pelas suas diferentes gravidades específicas, que certamente decorrem das diferenças nos números dos espaços vazios; e também do fato de que várias substâncias se insinuam através de suas substâncias [3, p. 127]. 
Portanto, no que tange à realidade microscópica, o testemunho dos nossos sentidos seria passível de suspeitas por estar notoriamente equivocado, induzindo-nos, por exemplo, a crer na extensão contínua como uma propriedade absolutamente necessária dos corpos. Caberia, então, a razão corrigir essa "miopia", possibilitando o refinamento da visão do pesquisador por meio de argumentos que o levariam a compreender mais do que o mesmo pode experimentar a partir dos sentidos. Isto não significa dizer que o jesuíta desconsidere os sentidos como fonte de um conhecimento real, em vez disto, ele parece pedir maior atenção ao considerar o peso que deve ser atribuído aos dados sensíveis na pesquisa científica [4, p. 120].

Com base nestas afirmações, não ficaremos surpresos pelo fato de Boscovich ter reservado uma posição de destaque, em sua epistemologia, ao papel heurístico das hipóteses, isto é, aos conceitos e asserções que não são inferidos diretamente da experiência sensorial. O jesuíta achará no próprio legado newtoniano razões que justificam o uso de hipóteses, mesmo que inverificáveis, em investigações sobre a natureza. Contrariando Newton, que afirmou ter deduzido a existência de forças a partir dos fenômenos [7, p. 187], Boscovich considerará que tanto a gravitação quanto a inércia não podem se inferidas diretamente dos fenômenos observados, sendo, portanto, hipóteses par excellence.

Todavia, de modo algum o status de hipótese descredenciaria a gravitação ou a inércia, pois, de acordo com Boscovich, a validade e relevância científica destas hipóteses independe de serem ou não extraídas diretamente dos fenômenos observados e tampouco exigem plena compreensão de uma natureza física intrínseca para serem aceitas, pois mais importante é o fato das respectivas hipóteses serem eficazes o bastante para explicar e determinar antecipadamente um grande número de eventos naturais. Sendo assim, se a gravitação e a inércia são em um contexto newtoniano - conceitos indemonstráveis com base nos fenômenos observados, nem por isto o jesuíta as toma como meras hipóteses arbitrárias, pois, conforme ressaltamos, o poder explicativo e preditivo é, segundo Boscovich, a melhor justificativa para uma hipótese científica, e se por ventura as observações viessem se mostrar contrárias às hipóteses inicialmente formuladas, isto seria mais que suficiente para demonstrar a falsidade destas [20, p. 385].

Convicto quanto a impossibilidade de deduzirmos leis naturais por meio da pura observação dos fenômenos naturais, Boscovich opta por seguir uma rota mais difícil, porém mais frutífera, em seu entender. O jesuíta fará, então, uso de um método de decodificação, partindo de conjecturas, comparando os resultados de várias tentativas, eliminado as conjecturas parcialmente eficazes ou malsucedidas para, com isto, alcançar um tipo de chave que dá à mensagem secreta um significado aceitável e a mantemos como solução até a descoberta de outra chave que dará um significado mais convincente [20, p. 387]. Para tal empreitada, o jesuíta afirma se valer da indu- ção e reconhece sua importância: Especialmente quando investigamos as leis gerais da natureza, a indução tem um poder muito grande; e dificilmente há outro método ao lado para a descoberta dessas leis [3, p. 57].

Muito embora considere a indução como sendo o único meio pelo qual a natureza pode ser estudada com esperança de sucesso, Boscovich a separa entre dois tipos: a completa e incompleta, sendo a última um tipo de indução fraca em seus fundamentos lógicos e, ainda assim, indispensável como instrumento de pesquisa [20, p. 388]. Segundo Boscovich, a despeito de a indução encontrada na física ser majoritariamente do tipo incompleta e, por conseguinte, carente de necessidade lógica, as leis alcançadas por intermédio dela gozam de uma validade geral. Caso surja um desacordo entre tais leis e os fenômenos observados devemos prontamente corrigir o que pode ser falso em nossas formulações e readequar as respectivas leis, tendo em vista que seria através de retrabalhos, correções e ampliações que o nosso conhecimento científico da natureza progride [20, p. 389].

\section{A física de Boscovich: A verdadeira dinâmica leibniziana}

\subsection{A Theoria de Boscovich}

O que ensejou o jesuíta à redação de sua obra magna Theoria Philosophiae Naturalis (1758) foi a sugestão feita pelo padre Karl Scherffer para que Boscovich investigasse o centro de oscilação (ou centro de percussão) dos corpos sólidos [3, p. xi.]. Esta pesquisa reconduziu Boscovich a uma problemática abordada em textos anteriores à Theoria: o fenômeno da colisão dos corpos. Ao se lançar na investigação sobre a produção e destruição de velocidades, como ocorre na colisão dos corpos, Boscovich foi levado ao estudo da distorção e recuperação da forma que ocorre no impacto. A partir disto, o jesuíta teria chegado à conclusão de que, devido a essa distorção e recuperação da forma, era produzido pelo impacto um retardo contínuo da velocidade relativa durante todo o tempo do impacto, que era finito [3, p. xi]. Em outros termos, o Princípio de Continuidade, tal como fora enunciado por Leibniz, foi constatado por Boscovich.

Sobre os estudos concernentes à colisão dos corpos, desenvolvidos em textos anteriores a Theoria, nos diz ainda o jesuíta nos artigos $\$ 16$ e $\$ 17$ de sua obra magna:

No ano de 1745, eu estava montando minha dissertação De Viribus vivis, e deduzi tudo o que os que aderem à ideia de Leibniz, bem como do número maior dos que medem as "forças vivas" só por meio da velocidade; derivam dessas "forças vivas" [...] Comecei então a investigar com um pouco mais de cuidado a produção de velocidade que se acredita surgir através de uma ação impulsiva, na qual toda a velocidade é creditada como sendo produzida em um instante de tempo, por causa disso, imagina-se que a força de percussão é infinita- 
mente maior que todas as forças que apenas exercem pressão por instantes isolados. Isto imediatamente me forçou a dizer que, para percussões desse tipo, que realmente produzem uma velocidade finita em um instante de tempo, seria necessário obter leis para suas ações diferentes das demais [3, p. 45].

Prossegue Boscovich:

No entanto, quando considerei o assunto mais detalhadamente, percebi que, se empregarmos um método direto de argumentação, esse modo de ação deveria ser retirado da natureza, a qual, na totalidade dos casos adere à mesma lei de forças e ao mesmo modo de ação. Cheguei à conclusão de que a ação impulsiva realmente imediata de um corpo sobre o outro, bem como a percussão imediata, não poderiam ser obtidas sem a produção de uma velocidade finita ocorrendo em um instante indivisível de tempo, e isso teria que ser realizado sem nenhuma mudança ou violação repentina da chamada Lei da Continuidade, lei que considerei existir na natureza, como pode ser demonstrado por um argumento suficientemente válido [3, p. 45].

Acompanhemos o raciocínio do jesuíta. Tomemos, pois, dois corpos iguais, um com velocidade de 6 graus e outro com velocidade de 12 graus, movendo-se na mesma direção em linha reta, estando o mais lento na frente do mais rápido. Levando em consideração a lei da conservação do momento, após o impacto, ambos se moveriam à velocidade comum de 9 graus. O problema surge neste ponto: como e quando os dois corpos passaram das duas velocidades iniciais para a final? Poder-se-ia supor o seguinte: Consideremos que o corpo mais veloz, que vem atrás, aproxima-se do outro sem diminuir a velocidade e entra em contato absoluto com o que segue à frente. Nesta situação, as velocidades dos corpos deveriam ser modificadas de forma abrupta de 6 para 9 e 12 para 9 graus respectivamente, sem passar pelos graus intermediários $\left(11\right.$ e $7 ; 10$ e $8 ; 9 \frac{1}{2}$ e $\left.8 \frac{1}{2}+\ldots.\right)$, visto que não é possível que esse tipo de mudança seja produzido por estágios intermediários em uma parte finita do tempo contínuo, por menor que ela seja, enquanto os corpos permanecerem em contato [3, p. 45-47]. Afinal, se em dado momento um dos corpos tivesse 7 graus de velocidade, o outro manteria 11 graus de velocidade. Deste modo, durante todo o tempo decorrido desde o início do contato (quando as velocidades são 12 e 6 graus), até o momento em que se tornam 11 e 7 graus, o segundo corpo deve ser movido com uma velocidade maior que a do primeiro, devendo, portanto, ter de percorer uma distância maior no espaço que o outro corpo. Disto decorre, dirá Boscovich, que a superfície frontal do segundo corpo deveria passar além da superfície traseira do primeiro corpo e, portanto, alguma parte do corpo que segue atrás seria penetrada por alguma parte do corpo que se move à frente [3, p. 47]. Mas tal assunção pressupõe uma interpenetração da matéria, algo que violaria uma propriedade universalmente reconhecidada da mesma: a impenetrabilidade. Outra possibilidade seria assumir que a mudança de velocidade ocorre abruptamente após a colisão, no entanto, isto configuraria uma clara violação do Princípio de Continuidade, já verificado pelo jesuíta. O mesmo problema se impõe se considerarmos que o mundo atômico é composto por átomos sólidos, conforme já observara Leibniz, pois se dois átomos fossem extensos com limites precisos, sua colisão deve necessariamente causar uma mudança abrupta em suas velocidades e, assim, contradizer o Princípio de Continuidade ([20], p. 391). Vemos, portanto, que os estudos sobre a colisão entre dois corpos sólidos levaram o jesuíta a um impasse cuja única maneira de sair seria mudar a base teórica sob a qual se movia ou abandonar a ideia de que as velocidades só podem começar a mudar após o contato entre os corpos [4, p. 107].

Na esteira desta problemática, já em De Viribus vivis podemos rastrear as primeiras ideias do jesuíta na formulação dos seus pontos materiais, uma entidade baseada na teoria das mônadas de Leibniz com algumas ressalvas. Veremos que, por um lado, os pontos de Boscovich aproximam-se das mônadas na medida em que seriam igualmente desprovidos de partes, extensão ou figura. Por outro difererem das substâncias simples do filósofo natural alemão na medida em que, em vez da força viva, a característica fundamental dos seus pontos materiais seria a ação à distância, concepção emprestada da teoria newtoniana [3, p. 35].

Nota-se, enfim, que as figuras, os conceitos e resultados de Newton e Leibniz se acham na vida intelectual de Boscovich muito antes da publicação da sua Theoria, fomentando problemáticas e reflexões que seriam determinantes para a elaboração de seu sistema teórico. Deste modo, não nos deve causar surpresa a declaração do jesuíta de que sua teoria das forças, sobre a qual refletira desde 1745 , apresenta um sistema a meio caminho entre o de Leibniz e o de Newton.

\subsection{Sobre os pontos materiais e a lei das forças}

Os axiomas centrais que se depreendem da Theoria Philosophiae Naturalis de Boscovich são: o Princípio de Continuidade e o Princípio de Impenetrabilidade [4, p. 106]. A tese principal do jesuíta está contida na ideia de que os elementos primários da matéria são pontos perfeitamente indivisíveis e não extensos [3, p. 37]. Os pontos materiais de Boscovich, embora dotados de inércia, não possuíam volume ou massa em sentido newtoniano, para ele, a massa de um corpo era determinada pelo número de pontos materiais que são combinados para formar o respectivo corpo [3, p. xiii]. Os pontos materiais estariam dispersos em um imenso vácuo e separados um do outro por uma certa distância, que pode aumentar ou diminuir indefinidamente, mas nunca desaparecer sem a compenetração destes pontos, uma vez que Boscovich veta a 
possibilidade de qualquer contato imediato entre eles [3, p. 39].

Ao despojar os átomos de toda a sua materialidade, Boscovich deixou apenas o movimento como a única maneira de determinar fenômenos, articulados pela ação de uma causa eficiente que preside às interações dinâmicas entre os elementos primários. Existiria, portanto, uma força mútua que depende da distância entre os pontos e que muda conforme a distância entre eles se altera, apresentando em alguns casos seu caráter atrativo e em outros o repulsivo [3, p. 39].

Muito embora conceba os átomos como sendo animados por forças atraentes e repulsivas nas quais repousa a mecânica newtoniana, Boscovich fomenta uma concepção de força distinta daquela empregada por Newton. Isto porque a proposta do jesuíta admite forças que a distâncias muito pequenas não são positivas ou atraentes, como supunha o filósofo natural inglês, mas negativas ou repulsivas, embora estas também se tornem cada vez maiores indefinidamente, à medida que as distâncias diminuem indefinidamente [3, p. 35]. Em suma, para o jesuíta, a força era uma determinação, ou propensão à aproximação ou ao afastamento e era medida pela aceleração produzida. Com isto, torna-se evidente que a mecânica de Boscovich era pura cinemática, baseada nas ideias primitivas de pontos materiais e de forças, ou seja, acelerações de aproximação ou de recuo [13, p. 219].

Retomando as suposições boscovicheanas sobre os pontos materiais, ao sabermos que tais pontos são centros que irradiam forças, poderemos inferir que o jesuíta termina por destituir o impacto como um conceito fundamental da dinâmica e reduz os fenômenos de contato a ações à distância entre os pontos [5, p. 388]. No impacto entre dois corpos a força entre eles haveria de ser repulsiva, pois lhes transmite uma propensão natural ao recuo recíproco um do outro. Ao passo que para distâncias maiores, de acordo com Boscovich, a força de repulsão mudaria de sinal e se transformaria em atração, o que explicaria os fenômenos comuns da gravitação, conforme veremos adiante.

Ademais, o jesuíta abarcará, em sua argumentação referente aos pontos materiais, tanto estruturas compostas por duas, três ou quatro partículas, quanto os sistemas maiores compostos por um número indefinido delas, tais como corpos sólidos, líquidos ou gasosos. Ao seguirmos seu engenhoso raciocínio, notaremos que Boscovich se propõe a reduzir todas as propriedades físicas observadas às interações entre os pontos, incluindo a extensão e a própria impenetrabilidade, que seria apenas a expressão espacial da ação de uma força repulsiva [13, p. 216].

Considerando a força a entidade que relaciona todos os elementos da realidade natural, o jesuíta se engajou em demonstrar que muitas das propriedades físicas conhecidas em sua época, relativas a colisões, coesão, som, barras rígidas e flexíveis, cristais, fluidos, mudanças de estados e gravitação, poderiam ser cobertas quantitativamente por uma lei de forças [21, p. 41]. Vejamos o que diz Boscovich a respeito dela:

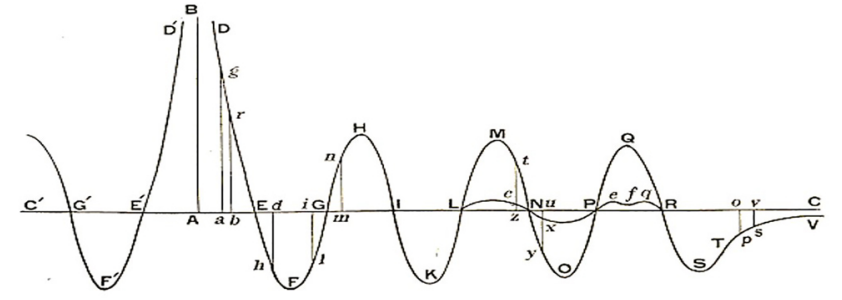

Figura 1: Representação gráfica da Curva da Força. Imagem extraída de [3]

A lei das forças é desse tipo; as forças são repulsivas a distâncias muito pequenas e se tornam indefinidamente maiores à medida que as distâncias diminuem indefinidamente, de tal maneira que são capazes de extinguir qualquer velocidade, por maior que seja, com a qual um ponto possa se aproximar de outro, antes que a distância entre eles desapareça. Quando a distância entre eles aumenta, elas [as forças repulsivas] diminuem de tal maneira que, a uma certa distância, que é extremamente pequena, a força se torna nada. Então, à medida que a distância aumenta, as forças são alteradas para forças atraentes; estas a princípio aumentam, depois diminuem, desaparecem e se tornam forças repulsivas, que da mesma maneira aumentam primeiro, depois diminuem, desaparecem e se tornam atraentes; e assim por diante: até que, finalmente, quando alcançamos distâncias relativamente grandes, elas começam a ser continuamente atraentes e aproximadamente inversamente proporcionais aos quadrados das distâncias [3, p. 39].

Tal lei de interação evidencia o caráter repulsivo da força para distâncias muito pequenas, mas cujo sinal alterna-se frequentemente conforme $r$, a distância entre dois pontos materiais, aumenta, e se aproxima assintoticamente da lei da atração newtoniana, quando $r$ tende ao infinito [21, p. 40]. De acordo com Boscovich, sua lei de forças poderia ser representada por uma única curva contínua [3, p. 43], conforme apresentado na Figura 1.

Sendo o sistema de Boscovich puramente cinemático, o jesuíta nos indica que a área de uma curva cujas abcissas representam distâncias e cujas ordenadas representam forças expressa o aumento ou a diminuição do quadrado da velocidade [3, p. 105]. Em termos estritos, o eixo das ordenadas, na Figura 1, representa apenas as acelerações. Seguindo o simbolismo matemático contemporâneo, teríamos:

$$
\text { Area }=\int a d x=\int \frac{d v}{d t} d x=\int v d v v_{2}^{2}-v_{1}^{2}
$$


Em uma curva deste tipo, conforme já indicado, o eixo das abcissas $\left(C^{\prime} A C\right)$ refere-se às distâncias entre dois pontos materiais ou centros de força, ao passo que o eixo das ordenadas $(A B)$ refere-se às forças decorrentes da interação entre os respectivos pontos. Quando as curvas estão acima do eixo $C^{\prime} A C$ estas denotam forças repulsivas e quando estão do lado inferior do mesmo eixo correspondem às forças atrativas, e conforme a curva se aproxima do eixo das abcissas ou se afasta dele as forças são diminuídas ou aumentadas.

A fim de termos uma compreensão mais detalhada da curva da lei de forças, tomemos como exemplo dois pontos materiais: um deles fixo no ponto Ae outro que pode se mover ao longo do eixo C'AC. Ao situarmos o segundo ponto em $d$, com base no gráfico, veremos a presença de uma força atrativa, de comprimento $d h$, entre os pontos. Por outro lado, ao situarmos o segundo ponto material em mconstataremos a existência de uma força repulsiva entre os pontos de comprimento $m n$. Acerca dos dois ramos da curva, um para cada lado do eixo $A B$, Boscovich considerará apenas um deles, já que tudo o que é dito sobre um pode estar diretamente relacionado ao outro [4, p. 111]. Ao tomarmos o ramo da curva DEFGHI$K L M N O P Q R S T V$, devemos atentar para os arcos ED e $S V$, que respectivamente se aproximam assintoticamente dos eixos $A B$ e $C^{\prime} A C$ : o arco $E D$, representa a situa-ção de dois corpos que estão entrando em contato e, neste caso, a intensidade da força cresce infinitamente, possibilitando que qualquer velocidade com a qual os corpos se aproximam seja extinguida. Enquanto o ramo $T V$ explicaria os fenômenos gravitacionais e, na prática, representa a mesma curva hiperbólica apresentada por Newton para descrever sua força gravitacional [4, p. 112]. Por esta razão, cumpre-nos ressaltar que a curva da lei de forças, que termina por combinar em uma única lei as forças observadas na natureza, resolve, por conseguinte, o problema observado por Boscovich referente à lei da gravitação universal, que carecia de modificações no caso de distâncias muito pequenas.

Caso sigamos a curva do primeiro arco assintótico $(E D)$ até o último $(S V)$, veremos que ela encontra o eixo das abcissas no ponto Epara, em seguida, decrescer em direção ao ponto $F$, onde a força mostra-se atrativa, aumentando sua intensidade à medida que se afasta do eixo das abcissas e se aproxima do ponto $F$. Após isto, a força atrativa começa a diminuir sua intensidade e à medida que a curva se aproxima novamente do eixo das abcissas, rumo ao ponto $G$, esta se transforma em força repulsiva. O mesmo processo repete-se nas demais interseções em decorrência das mudanças sucessivas da curvatura, até que, por fim, o gráfico termina no já mencionado arco assintótico $T V$, no qual a força permanece atrativa, diminuindo sua intensidade indefinidamente.

As interseções da respectiva curva nos fornecem ainda a chave para que entendamos a explicação de Boscovich no tocante a uma série de fenômenos [13, p. 217]. Neste ponto da análise do gráfico, dividiremos as interseções no eixo das abcissas em dois tipos: limites de coesão (quando a força passa de repulsiva para atrativa) e limites de não coesão (quando a força passa de atrativa para repulsiva). Os limites de primeiro tipo relacionados a $E, I, N$ e $R$ correspondem a pontos de equilíbrio estáveis, tendo em vista que a força experimentada pelo segundo elemento de matéria em qualquer uma dessas posições é zero e qualquer ligeiro deslocamento deste elemento resulta em uma força que tende para o reestabelecimento deste à posição de equilíbrio [22, p. 188]. De modo que, se a distância for aumentada por uma força repulsiva, uma força atrativa surge, mas se a distância é diminuída pela atrativa uma força repulsiva surge restaurando a posição de equilíbrio [3, p. 149]. Estes pontos relacionam-se ao fenômeno de coesão, isto é, a razão das partículas se unirem formando agregados maiores até que, finalmente, constituam os corpos. Assim, o problema da descrição de um corpo sensível poderia ser reduzido à construção de uma configuração estável de um número finito de pontos materiais [22, p. 191]. Inversamente aos primeiros, os limites de segundo tipo relacionados a $G, L e P$, correspondem a pontos de equilíbrios instáveis, pois um leve deslocamento de qualquer um deles é acompanhado por uma força direcionada para longe da posição de equilíbrio [22, p. 188]. No entanto, sobre qual seria o número de interseções, Boscovich permanece um tanto vago. Ele explica através de um argumento que elas devem ser numerosas (ou melhor, é altamente provável que sejam), mas de modo algum fornece uma quantificação precisa [4, p. 113]. Sua curva é, portanto, exclusivamente qualitativa, visto que o jesuíta se reserva o direito de dar qualquer determinação em termos de quantidade. Aqui nos convém pontuar que o fato do trabalho de Boscovich permanecer desprovido de determinações quantitativas expõe uma das principais debilidades de seu sistema teórico. Ao ver-se incapaz de oferecer qualquer equação que defina a curva de forças com precisão, Boscovich arguirá que o número de interseções da curva com o eixo das ordenadas, ou seja, os pontos em que a força muda de repulsiva para atrativa, é algo que deve permanecer desconhecido para a pesquisa científica, embora seja possível imaginar que é muito alto a partir da observação das qualidades de alguns elementos. Mais seguro seria inferir que, para o jesuíta, este seria um conhecimento exclusivo do Criador, não competindo aos cientistas desvendá-lo. $\mathrm{Na}$ esteira disto, afirma Gori:

As declarações sobre a impossibilidade de um conhecimento absoluto no campo da física são facilmente explicadas, considerando que o trabalho do dalmaciano continua sendo o trabalho de um religioso, que favorece abertamente a separação entre ciência e teologia. Consistentemente com sua figura de jesuíta, ele justifica a impossibilidade de enfrentar um certo tipo de pesquisa para a qual a técnica de sua época ainda não estava preparada [4, p. 129].

A exposição acima nos dá uma amostra da sofisticada teoria desenvolvida pelo dalmaciano Ruggero Boscovich 
que, com o objetivo inicial de esclarecer e resolver algumas dificuldades que o sistema de Newton deixou em aberto, voltou-se para as conclusões apresentadas por Leibniz e foi capaz de estabelecer uma interessante conexão entre dois sistemas teóricos aparentemente antagônicos. Graças à união de aspectos importantes da física de Newton e Leibniz (ação à distância e teoria das mônadas), Boscovich criou um modelo que superava o corpuscularismo cartesiano e tornava a força a única realidade do Universo, e a partir dela ser possivel compreender todas as propriedades da matéria, que se constituiram exclusivamente através da interação dinâmica dos numerosos pontos materiais dispersos no vácuo. Enquanto Newton restringiu-se a três fenômenos elementares (gravidade, coesão e fermentação), o jesuíta, com sua lei de forças, foi capaz de explicar todos os princípios naturais, ou seja, Boscovich se engajou em formular uma única lei geral capaz de dar conta de toda a dinâmica natural que a ciência do século XVIII pensou que poderia identificar [4, p. 127].

\subsection{A conservação da vis viva}

Além de significar uma superação do corpuscularismo cartesiano, a teoria de Boscovich representou ainda uma conclusão lógica daquele projeto não avançado por Leibniz, conforme sustenta o filósofo e matemático britânico Bertrand Russell:

A teoria relacional do espaço e toda sua doutrina das mônadas deveriam tê-lo levado [Leibniz], como levou Boscovich, Kant e Lotze, à teoria dos centros de força não extensos. $\mathrm{O}$ fracasso em escolher entre essas alternativas fez de sua dinâmica uma massa de confusões. A verdadeira dinâmica leibniziana não é dele, mas de Boscovich. Essa teoria é um desenvolvimento simples da Dinâmica Newtoniana, na qual toda a matéria consiste em pontos materiais, e toda ação é ação à distância ([23], p. 91).

Boscovich apropriou-se tanto da teoria das mônadas quanto das concepções de espaço e tempo de Leibniz, o que obviamente denota a estreita relação entre as propostas dos dois pensadores [4, p. 125]. Mas há ainda outro aspecto que conecta Boscovich e Leibniz, e endossa ainda mais a ideia de Russell de que o modelo teórico do jesuíta representa uma espécie de conclusão do que seria a "verdadeira dinâmica leibniziana", a saber, a conservação da vis viva.

Para tratar deste tema, devemos rememorar, brevemente, a controvérsia da vis viva que continuou ao longo do século XVIII com Samuel Clark e Dortous de Mairan defendendo os cartesianos contra Johan Bernoulli e Christian Wolff defendendo as ideias de Leibniz [24, p. 129]. A controvérsia teve suas raízes na lei de Descartes sobre a quantidade de movimento, conforme discutido em seu Principia Philosophiae de 1644. Descartes acreditava que Deus, a causa geral de todo movimento no universo, preserva a mesma quantidade de movimento e repouso colocados no mundo no momento da criação. Para o matemático francês, a conservação da quantidade de movimento seria derivada da perfeição de Deus, pois o Criador é em si imutável e todas as suas operações são realizadas de maneira perfeitamente constante e imutável. Existiria, portanto, uma quantidade absoluta de movimento que, para o universo, permanece constante. A medida dessa quantidade seria $m v$. A partir da aplicação do princípio de Descartes em suas regras que regem a colisão de corpos, essa quantidade, $m v$, conservaria apenas a magnitude da quantidade de movimento e não sua direção, isto é, a velocidade é sempre tratada como uma quantidade positiva, $|v|$ e não como uma quantidade vetorial cuja direção é variável. A partir de 1686, Leibniz escreveu uma série de artigos argumentando que a quantidade que permanece absoluta e indestrutível na natureza não é quantidade de movimento, mas a vis viva ou força viva, expressa por $m v^{2}$. Os argumentos de Leibniz são direcionados contra a inadequação com que a medida da matéria em movimento de Descartes, $m|v|$, descreveu o mundo físico. Conforme frisamos, a força viva, era tida por Leibniz como a essência da natureza, um princípio abrangente, a base para toda a sua filosofia. Assim, a controvérsia inicial da vis viva não parecia ser uma controvérsia sem sentido sobre momento versus força viva, mas um ataque hábil de Leibniz contra um conceito a seu ver inadequado, $m|v|$ e sua descrição do mundo [15, p. 21-23].

Boscovich, por sua vez, considerava a controvérsia uma mera disputa de palavras e demonstrou a diferença entre os efeitos do momento e da força viva usando o diagrama geométrico abaixo.

Empregando as categorias escolásticas antigas e os novos métodos matemáticos de sua época, o jesuíta discutiu a representação gráfica de uma pressão aplicada ao longo do tempo e uma força aplicada à distância. Analisemos o gráfico pormenorizadamente. No diagrama de Boscovich (Figura. 2), imagina-se que uma pressão EF aumente ao longo de um tempo $A C$ (em termos modernos, o diagrama plota a variação da "pressão" como uma função do tempo). Mas o tempo pode ser dividido em seus elementos infinitesimais ou tempúsculo. De modo que, se

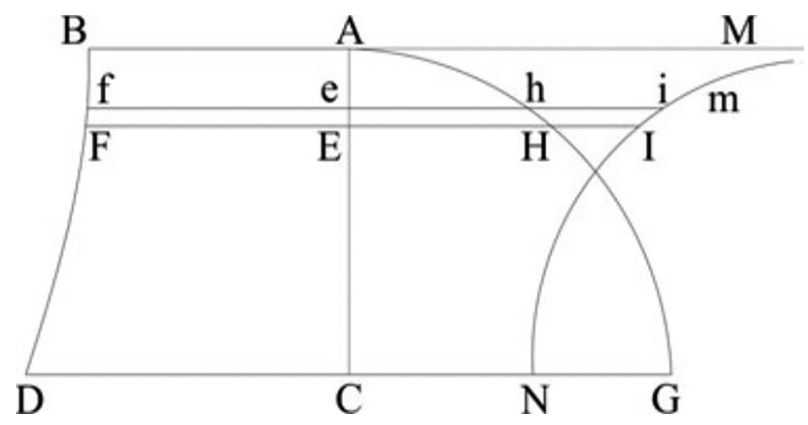

Figura 2: Representação gráfica de Boscovich do momento e da força viva, gerada por "pressões" de ação instantânea. Imagem extraída de [5]. 
o espaço $E$ e é considerado indefinidamente pequeno, por causa da diferença indefinidamente pequena entre os segmentosef e $E F$, a pequena área FEef é imaginada como um retângulo. Ademais, em decorrência da diferença infinitesimal entre duas pressões instantâneas em um tempúsculo indefinidamente pequeno, neste mesmo tempúsculo, mesmo um movimento acelerado não uniforme é pensado como um movimento uniformemente acelerado. Sabendo que as pressões provocam mudanças instantâneas na velocidade, isto é, elas produzem acelerações em cada tempúsculo Ee a equação $v=a t$ se mantém ou, nos termos geométricos sugeridos pelo diagrama de Boscovich, a área $B A E \mathrm{~F}$ (velocidades instantâneas de $B \mathrm{~A}$ a $E F$, ou o incremento $d v$, durante o tempo $A E$ ) representa uma velocidade. Quando pensadas ao longo do tempo, as forças são medidas através das velocidades simples em oposição ao seu quadrado, e a ação de potências que geram pressões ou velocidades- a ação que chamamos de força dessas potências- é medida a partir da composição das velocidades geradas nas partículas individuais, ou seja, multiplicando a massa por uma única velocidade [5, p. 403]. O resultado final é o momento como a medida da força quando a força é vista como agindo ao longo do tempo. De acordo com a terminologia contemporânea, o momento, $m v$, seria representado como a integral daquelas pressões ou impulsos instantâneos ao longo do tempo [25, p. 139].

$$
\int m d v=\int p d t
$$

Se chamarmos, agora, a coordenada $A C$ de espaço percorrido em vez de tempo em que uma ação ocorre e a coordenada $E F$ de força que a qualquer instante produz a velocidade proporcional a ela em vez de pressão, um segundo aspecto do fenômeno pode ser representado, já que a coordenada $B A E F$ não mais corresponderá a uma velocidade, mas será proporcional ao quadrado da velocidade. De fato, a força $E F$ gera uma velocidade proporcional a $E F$ e ao tempo em que a respectiva força atuou ([5], p. 404). Na notação matemática contemporânea teríamos:

$$
d v=E F \cdot d t
$$

Agora, se assumirmos que em um segmento infinitesimal Ee um ponto se move com movimento linear uniforme devido a ação da força $E F$ no instante do tempo correspondente à posição $E$, teremos que o tempo correspondente a $E e$ será proporcional ao espaço percorrido e inversamente proporcional à velocidade:

$$
d t=\frac{E e}{v}
$$

Sabendo que $E F$ representa a força e $E e$ um espaço infinitesimal, aplicamos uma substituição conveniente e obtemos:

$$
\begin{aligned}
& d v=E F \cdot \frac{E e}{v} \\
& \therefore \\
& v \cdot d v=E F E e
\end{aligned}
$$

Finalmente, aplicando o método infinitesimal, Boscovich conclui que o quadrado da velocidade de um corpo que parte de $A$ (onde estava em repouso) é proporcional à pequena área $B A E F$. Em outros termos, a força, como uma função do espaço, é medida pelo quadrado de uma velocidade [5, p. 404]. Ao introduzirmos as massas 5 chamando de EF de $F$ (força) e $d s=v d t$, poderíamos interpretar a força viva à luz da notação matemática contemporânea como:

$$
\int F d s=\int m v d v
$$

Vê-se que a análise matemática de Boscovich contém os elementos necessários para distinguir a força: $m v^{2}$ como uma função dependente do espaço e $m v$ como uma função dependente do tempo [24, p. 134]. O jesuíta afirmou que a controvérsia entre leibnizianos e cartesianos não passava de uma "disputa de palavras" em virtude das quantidades fundamentais da mecânica (espaço, tempo e velocidade como uma relação entre o espaço e tempo percorrido) serem interpretadas corretamente em ambos os casos [5], p. 402].

No entanto, do ponto de vista da realidade física, Boscovich pendia para o lado dos cartesianos, pois considerava que o momento $m v$ era a verdadeira medida da "força de movimento", sendo a força viva válida apenas como método de cálculo, conforme detalha Carolyn Iltis:

Boscovich acreditava que o momento $[m v]$ era a verdadeira medida da força, vis viva $\left[m v^{2}\right]$ seria válida apenas como método de cálculo. Em seu De Viribus Vivis, bem como em seu posterior Philosophiae Naturalis Theoria (1758), ele argumentou que não havia forças vivas na natureza. Assim, Boscovich, apesar de fornecer uma visão que teoricamente ajudou a resolver a controvérsia vis viva, não reivindicou status igual para os dois princípios no tratamento de problemas físicos $[25$, p. 140].

Para Boscovich, não só a quantidade de movimento, $m v$, seria a verdadeira medida da força como também seria a quantidade que permanece absoluta e indestrutível na natureza, conforme nos diz no artigo §264 da Theoria:

A quantidade de movimento no Universo é mantida sempre a mesma, desde que seja computada em uma determinada direção, de modo que o movimento na direção oposta seja considerado negativo, e a soma dos movimentos contrários seja subtraída da soma dos movimentos diretos [3, p. 203].

Este seria o único princípio de conservação que Boscovich explicitamente aceitaria. O curioso é notar que, ao mesmo tempo em que argumentava vigorosamente contra a conservação da força viva e rechaçava a ideia

\footnotetext{
5 Boscovich não traz a massa para essa análise ([25], p. 139).
} 
de qualquer força ativa na matéria - não à toa a rejeitou como característica fundamental dos seus pontos materiais - Boscovich forneceu, ainda que involuntariamente, uma explicação plausível para a conservação da força viva defendida por Leibniz [18, p. 292].

Uma das críticas mais recorrentes à proposta do filósofo natural alemão sobre a conservação da força viva é a frequência com que ela parecia ser violada. A força leibniziana era destruída em colisões inelásticas, mas Leibniz, que negava a possibilidade de ações à distância, acreditava suficientemente em sua teoria para postular que o movimento era retido nas partes dos corpos graças a uma matéria infinitamente fluída que tinha partes menores. Diz ele em sua quinta carta endereçada a Clarke:

É verdade que suas totalidades a perdem [alguma força] em relação ao movimento total, mas suas partes a recebem, sendo abaladas pela força do concurso ou do choque. E, portanto, essa perda de força é apenas na aparência. As forças não são destruídas, mas espalhadas entre as pequenas partes [dos corpos] [26, p. 59].

Com sua teoria, Boscovich fornece uma explicação perfeita de como o movimento dos corpos em colisão pode ser "absorvido pelas pequenas partes". Se todos os corpos são constituídos por pontos materiais, quando estes pontos são deslocados de seus "pontos de coesão" (talvez, por uma colisão), eles estarão sujeitos a uma força restauradora e oscilarão sobre o ponto limite de coesão pelo qual passaram. Boscovich percebeu que era necessária alguma força externa para pôr fim às oscilações dos pontos materiais.

Nesse ponto limite [coesão], em ambos os casos, a separação ou a abordagem, devido às forças que precederam, será alterada e a velocidade do movimento começará a ser diminuída por uma força oposta à força original, mas o movimento continuará na mesma direção; até que uma área da curva sob o arco que segue o ponto limite se torne igual à área sob o arco anterior desde o início do movimento até o ponto limite [ver Figura 3]. Se a igualdade desse tipo for obtida em algum lugar sob o arco subsequente, então, toda a velocidade precedente será destruída, ambos os pontos retornarão ao longo de seus caminhos; e se no início eles se aproximaram, agora começarão a se afastar um do outro, ou se originalmente se afastaram um do outro, agora começarão a se aproximar; e, ao fazerem isso, recuperarão pelos mesmos estágios as velocidades que perderam, até o ponto limite pelo qual passaram; então eles perderão aqueles que haviam adquirido, até alcançarem a distância que tinham no começo [3, p. 149].

Em suma, Boscovich acreditava que, nas colisões inelásticas, as partículas eram deslocadas até chegarem a

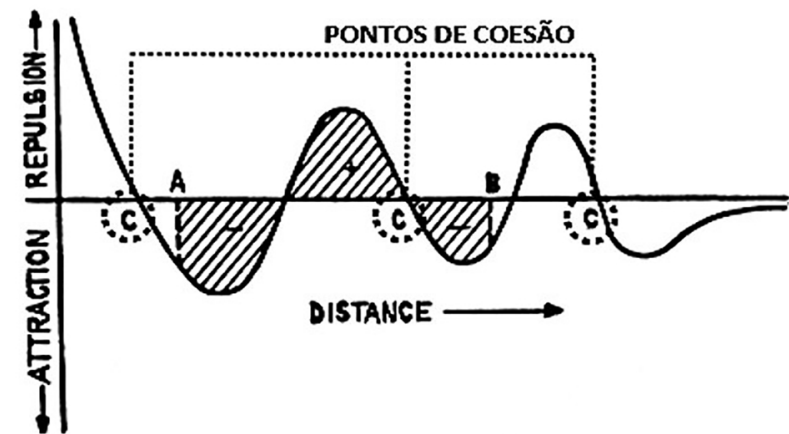

Figura 3: Representação gráfica da Curva da Força. Imagem adaptada de [18].

novos pontos de coesão e, dessa maneira, a "força" seria armazenada, já que o movimento seria recuperado quando as partículas retornassem às suas posições originais $[18, \mathrm{p}$. 293]. De acordo com a curva de forças, se uma partícula é deslocada de um ponto de coesão, sua mudança na velocidade pode ser facilmente determinada, uma vez que a área limitada pela curva e pelo eixo é proporcional ao quadrado da velocidade. Boscovich afirmou esse fato e o derivou usando cálculo [3, p. 141; nota [m] ].

Em notação matemática moderna, entre quaisquer dois limites $(A$ e $B)$, a área delimitada pela curva e o eixo tomado em relação ao sinal é igual a:

$$
\int_{A}^{B} \rho d x=\frac{1}{2} m v_{b}^{2}-\frac{1}{2} m v_{a}^{2}
$$

Empregando uma formulação contemporânea, a derivação matemática de Boscovich mostra que, em seu sistema teórico, a força viva ou energia cinética é sempre conservada, muito embora seja frequentemente "armazenada" na forma de energia potencial. Em qualquer movimento relativo de dois pontos materiais, os respectivos pontos podem perder energia cinética, mas quando retornam às suas posições originais, essa energia é restaurada. Não há nenhuma perda de energia por atrito ou colisão no sistema do jesuíta, já que os seus pontos materiais nunca entram em contato [18, p. 294].

Vê-se, enfim, que onde Leibinz falhou, Boscovich obteve êxito. A elaboração de um modelo que assegurava a conservação da força viva é, ainda que involuntariamente, realização do jesuíta e se mostra como outro forte argumento para que sua física represente a completude do que seria a "verdadeira dinâmica leibniziana", conforme frisou Russell

\section{Conclusão}

Embora não tenha atingido a mesma visibilidade de Newton e Leibniz, o inovador trabalho de Boscovich foi lido e comentado por algumas importantes figuras do âmbito científico dos séculos XVIII e XIX, tais como Joseph Priestley [27, p. 161], William Thomson (Lorde Kelvin) e Michael Faraday. Quanto ao último, o biógrafo Leslie Pearce Williams insiste que Faraday teria endossado as 
ideias de Boscovich enquanto formulava suas teorias sobre força e natureza da matéria. Williams ressalta que Boscovich ofereceu a justificativa para a unidade da matéria em que Faraday e Davy acreditavam ([28, p. 530]. Para o pupilo de Davy, uma guinada das ciências naturais ao sistema de Boscovich, embora não representasse grande alteração nos resultados no âmbito da cristalografia, da química e magnetismo, seria proveitosa e promoveria grandes mudanças em outros domínios, tais como a condução elétrica, a natureza da luz, a maneira como os corpos se combinam para produzir compostos, os efeitos das forças, como calor ou eletricidade, sobre a matéria [29, p. 141]. Inclinado às concepções de Boscovich sobre as partículas materiais, Faraday não as via como bolas de bilhar submicroscópicas às quais certas forças bastante simples estavam associadas, mas como centros de uma complexa teia de forças [28, p. 532].

Ademais, embora o sistema teórico expresso na Theoria consista em uma série de hipóteses ou meditações que não podiam ser experimentalmente verificadas, tendo em vista que, naquela época, certas experiências ainda não eram tecnologicamente viáveis, Ruggero Giuseppe Boscovich abriu caminho para a reflexão especulativa na ciência, sendo capaz de dar um amplo salto para além dos sentidos em sua investigação da realidade natural [30, p. 73]. Por esta razão, o papel que as investigações de Boscovich desempenharam no âmbito científico foi objeto de interesse de Karl Popper em uma palestra apresentada em Veneza, no ano de 1958, onde discutia sobre a contribuição da ciência moderna para elucidação de problemas de natureza filosófica, em especial sobre questões concernentes à matéria. Segundo Popper, alguns problemas relacionados a teoria da matéria teriam sido resolvidos, em colaboração, por filósofos naturais como Descartes, Leibniz, Kant e o próprio Boscovich, que com sua epistemologia puramente especulativa propôs soluções importantes e preparou o caminho para o trabalho de cientistas experimentais e teóricos como Faraday, Maxwell, Einstein, de Broglie e outros [31].

\section{Agradecimentos}

Este trabalho foi realizado com o apoio de órgãos de fomento à pesquisa científica. Em razão disto, Wigson Rafael Silva da Costa agradece a bolsa de mestrado, $\mathrm{n}^{\circ}$ 200.690/2019 (243079), concedida pela Fundação Carlos Chagas Filho de Amparo à Pesquisa do Estado do Rio de Janeiro (FAPERJ) e Antonio Augusto Passos Videira agradece a bolsa de produtividade, $\mathrm{n}^{\circ} \quad 304.945 / 201-5$, concedida pelo Conselho Nacional de Desenvolvimento Científico e Tecnológico (CNPq), bem como ao Programa Prociência UERJ/FAPERJ.

\section{Referências}

[1] D.J.K. O'Connell, Studies: an Irish quarterly review 51, $487(1962)$
[2] Z. Markovic, em: Dictionary of scientific biography, editado por C.C. Gillispie (Charles Scribner's sons, New York, 1981), v. 2.

[3] R.J. Boscovich, A Theory of natural philosophy (Open Court Publishing Company, Chicago-London, 1922).

[4] P. Gori, La visione dinamica del mondo: Nietzsche e la filosofia naturale di Boscovich (La cittá del sole, Napoli, 2007).

[5] L. Guzzardi, Science in Context 30, 385 (2017)

[6] I. Newton, Principia: Princípios Matemáticos de Filosofia Natural - Livro I (Editora da Universidade de São Paulo, São Paulo, 2012a).

[7] I. Newton, Principia: Princípios Matemáticos de Filosofia Natural - Livro II e III (Editora da Universidade de São Paulo, São Paulo, 2012b).

[8] R.A. Martins e C.C. Silva, Revista Brasileira de Ensino de Física 37, 4202 (2015).

[9] I. Newton, Isaac. Óptica (Editora da Universidade de São Paulo, São Paulo, 1996).

[10] J.K. Mcdonough, The Stanford Encyclopedia of Philosophy (Stanford University, Stanford, 2007).

[11] E. Marques, O que nos faz pensar 14, 183 (2004).

[12] R.L. Ponczek, Caderno Catarinense de Ensino de Física 17, $336(2000)$.

[13] M. Jammer, O conceito de força: Estudos sobre os fundamentos da dinâmica (Contraponto, Rio de Janeiro, 2011).

[14] P. Costabel, Leibniz and dynamics: The texts of 1692 (Cornell University Press, New York, 1973).

[15] G.W. Leibniz, Discurso de Metafísica (Edições 70, Lisboa, 2017).

[16] C. Iltis, Chicago Journals: The History of Science Society 62, 21 (1971).

[17] G.W. Leibniz, A Monadologia e outros textos (Hedra, São Paulo, 2009).

[18] T.L. Hankins, Isis 56, 281 (1965)

[19] R.S. Westfall, Never at rest: A biography of Isaac Newton (Cambridge University Press, New York, 2010).

[20] M.D. Grmek, Revue d'histoire des sciences 49, 379 (1996)

[21] L.L. White, Records of the Royal Society 13, 38 (1958).

[22] B.J. Spencer, Archive for History of Exact Sciences 4, 184 (1967).

[23] B. Russell, A critical exposition of the Philosophy of Leibniz, with an Appendix of leading passages (University Press, London, 1900).

[24] E. TakimotoO que há de metafísica na Mecânica do Século XVIII? Tese de doutorado, Universidade do Estado do Rio de Janeiro, Rio de Janeiro (2013).

[25] C. Iltis, Studies in History and Philosophy of Science 1, 135 (1970).

[26] G.W. Leibniz, Correspondence: G. W. Leibniz and Samuel Clarke (Hackett Publishing Company, Indianapolis, 2000).

[27] B.A. Moura, Transversal: International Journal for the Historiography of Science 5, 157 (2018)

[28] P.L. Williams, em: Dictionary of scientific biography editado por C.C. Gillispie (Charles Scribner's sons, New York, 1981). v. 4.

[29] M. Faraday, The London, Edinburgh and Dublin Philosophical Magazine and Journal of Science 24, 136 (1844).

[30] P. Gori, Memorie della Società Astronomica Italiana 22, $64(2013)$ 
[31] K. Popper, The Myth of the framework (Routledge, London, 1994). 